\title{
Regression model to predict thread consumption incorporating thread-tension constraint: study on lock-stitch 301 and chain-stitch 401
}

Ranga Prasad Abeysooriya and Ganemulle Lekamalage Dharmasri Wickramasinghe*

\footnotetext{
*Correspondence: dharmasri@uom.lk Department of Textile and Clothing Technology, University of Moratuwa, 10400 Moratuwa, Sri Lanka
}

\begin{abstract}
Prediction of sewing thread consumption requires an accurate method of calculation since it relates to the cost of manufacturing and distribution of apparel products. Previous researchers highlighted problems in existing thread consumption calculation methods; i.e. limitations in existing formulae which cause inaccurate predictions of thread amount needed for sewing operations. The existing methods of consumption calculations exhibit significant error percentages due to the ignorance of important parameters which affect on thread consumption. This paper investigates on correlation of thread tension to thread consumption of lock-stitch 301 and chain-stitch 401. The existing thread consumption formulae are optimized by considering a new parameter; thread tension, using regression analysis and geometrical modeling techniques. For the chain-stitch 401, results indicate that the thread tension significantly affects in determination of the thread consumption. The error analysis of proposed formulae was performed to indicate that the proposed formulae more accurate compared to the available methods of predicting sewing thread consumption. In addition, there are combined effects of thread tensions together with parameters such as fabric thickness and stitch density which determines accurate consumption values considering the properties of the stitch. In comparison, inclusion of the proposed thread tension variable depicts reduction in error percentages, so that the proposed formulae are expected to be a better approach to calculate thread consumption of lock-stitch 301 and chain-stitch 401.
\end{abstract}

Keywords: Sewing thread consumption; Thread tension; Stitch density; Fabric thickness; Stitch type; Regression analysis

\section{Introduction}

Prediction of sewing thread consumption is one of the significant factors in thread procurement. In apparel industry both garment manufacturers and thread suppliers predict thread consumption per unit length of stitch for their thread purchasing and logistics processes. Inaccurate thread consumption predictions lead to inaccurate costing and reduction of warehouse utilization for both garment manufacturers and sewing thread manufacturers. Purchase of excess or shortage quantities of thread cones make suppliers to endure those excess or shortage thread quantities, so that both parties undergo inflexible logistic process (Jaouadi et al. 2006). In this context sewing thread manufacturers and garment manufacturers are looking for accurate method

\section{Springer}


predicting sewing thread consumption for given stitch lengths so that wastages could be minimized.

Therefore, objective of this paper is to review theoretical and practical approaches of sewing thread consumption prediction methods based on the literature and to propose new method incorporating thread tension parameter. Thread consumption formulae were derived by investigating the effect of thread tension for two basic types of stitches namely lock-stitch 301 and chain-stitch 401. Accuracy of those optimized formulae was measured through an error analysis by comparing theoretical and actual thread consumption values. The error percentage values of the newly developed formulae were compared with the other methodologies developed by other researchers and sewing thread manufacturers for calculating sewing thread consumption.

\section{Literature review}

Researchers and sewing thread manufacturers had different approaches in developing thread consumption calculations. Thread length required for a unit length of a stitch is the most frequent measurement (Ukponmwan et al. 2000) which provides flexibility to calculate the thread consumption for a given length of stitch. Measuring the actual length of threads in the stitch is one prominent method which gives correct results if measuring standards are properly followed. Actual lengths of thread are measured by unraveling the formed stitch carefully under correct tension of threads. Unraveled threads are measured following standard testing methods since they are in-build with crimp. As an example, the French standard NF G07 101 is used to determine the unraveled thread lengths (Jaouadi et al. 2006). Though unraveling method gives an accurate value, the stitching operation has to be performed several attempts to improve the accuracy by optimizing sewing parameters. The measuring process is time consuming and it requires testing cost for material, and equipment and people. Test operator should be highly skilled person to obtain exact values of yarn lengths without exposing them to excessive tensions or distortions.

With these drawbacks of the actual measurement of thread consumption, researchers approached on prediction techniques applicable to determine thread consumption as quick and viable solution. Value prediction charts, mathematical formulae, thread length ratios, predictive algorithms based on past data, learning algorithms and software solutions (Jaouadi et al. 2006) are several methods available in literature which use to predict the thread consumption. When analyzing the prediction values of each techniques for a given stitch length with same input parameters in same stitch configuration, it has shown a significant scattered behavior as well.

Jaouadi et al. (2006) reveals that parameters such as stitch density, fabric thickness, thread linear density and seam width are mainly being used to predict sewing thread consumption. In practice, garment manufacturers calculate thread requirement based on consumption estimate charts provided by specific thread suppliers (Carr \& Latham 1994; Amann Group 2010; American \& Efird Inc 2007). The charts calculate thread consumption using different variables and assumptions. They either estimate approximated thread consumption per garment or thread requirement per unit length of the stitch. Since these charts can be used under given specific scenarios; i.e. for given set of stitch densities or for a given thickness of fabric etc., it provides less flexibility in using for varying stitch densities and fabric thicknesses. 
Introduction of consumption ratios is another prediction technique which decides ratio of thread amount with respect to the geometry of the stitch. Different ratios were derived as per the stitch types though these ratios have limited to one stitch density value. To overcome these disadvantages, thread suppliers subsequently developed consumption ratios for selected stitches which facilitate calculation of thread consumption for given set of stitch densities and fabric thickness values (Amann Group 2010; American \& Efird Inc 2007).

Most of leading thread suppliers currently uses software packages to improve the efficiency of thread consumption calculation with different formulae and ratios. These software packages are capable on calculating thread consumption for varying parameters such as stitch lengths, stitch densities, fabric thickness etc. Majority of stitchclasses used in the apparel sector have been defined in these systems. Parameters such as seam widths are also included with the appropriate stitch type. Unlike previous techniques, thread consumptions are calculated separately for needle threads, bobbin threads and looper threads. Though certain software solutions address thread properties such as ticket number for thread consumption calculations, majority of solutions have not addressed some critical physical properties which associates stitch formation.

Previous studies specify parameters such as stitch type, stitch density, fabric thickness, and seam width determine correlation to the thread consumption as per the stitch type being considered (Samuel \& Poojitha 2010; Jaouadi et al. 2006). Experimental study of Jaouadi et al. (2006) on cloth thickness and stitch density revealed a significant effect on thread consumption with a positive correlation for stitch types 301, 401, 504 and 516. In addition to fabric thickness and stitch density, yarn count of the thread has influenced on thread consumption. Further, they revealed that fabric type do not have a statistically significant effect on thread consumption (Jaouadi et al. 2006).

In previous studies by Rengasamy and Samuel (2011) on needle thread tension for lock-stitch 301, four tension peaks have been signified by measuring the online tension of stitch formation. They reported that the threads are extended dynamically at the tension peaks mainly when needle descends and penetrate through the fabric during the stitch formation (Rengasamy \& Samuel 2011). Especially in stitch tightening; the last step of the stitch formation produces highest tension peak also apply an extension to the sewing thread (Weimer \& Mitschang 2001; Rengasamy \& Samuel 2011). Thread tension was identified as one of the important parameters which influence the quality of the seam in garment construction. Krishnan and Kumar (2010) have attempted developing reliable tension measuring devices to measure on-line tension of the running thread. Ferreira et al. (1994a, b, c) have studied thread tension on lock stitch sewing machine and investigated the tension behavior of both the needle-thread and bobbinthread.

Some researchers have approached theoretical techniques such as neural networks, statistical and geometrical methods to calculate sewing thread consumption (O'Dwyer \& Munden 1975; Hayes 2001; Kennon \& Hayes 2000; Jaouadi et al. 2006; Ukponmwan et al. 2000; Amirbayat \& Alagha 1993). Jaouachi et al. (2012) developed a method to calculate the consumption of the sewing thread of jean pant using taguchi design analysis. The recent efforts of thread consumption research (Jaouachi et al. 2012; Rasheed et al. 2014; Ghosh \& Chavhan 2014) demonstrate that still researchers tend to examine on better formulae to minimize the errors occur in using the existing formulae. 
However, thread tension has not been taken as a parameter for any of the above studies. This study investigates the influence of thread tension to the thread consumption of lock-stitch 301 and chain-stitch 401 while incorporating the parameters which had been already been examined by previous authors (Jaouachi et al. 2012; Rasheed et al. 2014; Ghosh \& Chavhan 2014).

\section{Methods}

Experiments were designed to evaluate the variation of thread consumption with respect to the considered parameters; stitch density (SPI), thickness of the fabric, yarn count and tension of the thread. The experiments were conducted using $100 \%$ cotton woven fabrics and the fabric type remained constant though Jaouadi et al. (2006) revealed that the fabric type has no significant effect on sewing thread consumption. Stitch quality was always one of major concerns when accepting a certain result as a data point and which was evaluated by quality control experts with reference to the stitched quality standard ASTM D6193, standard practice for stitches and seams (ASTM International 2011).

As per the stitches selected; lock-stitch 301 and chain-stitch 401, recommended thread types of poly/poly core-spun threads (with polyester continuous filament core and polyester staple wrap) were used. Yarn count of the thread was taken instead of the thread ticket number value to minimize the approximation errors occurring in ticket number calculations. Fabric thickness was measured following the test standard of BS2544, methods for determination of thickness of textile materials (British standards institution 1987). Yarn counts of threads were measured using ASTM D1907, standard method of test for yarn number by the skein method (ASTM International 1997). Thread consumption and average thread tension were measured using MLT Wesco tension and length meter with the accuracy up to $1 \mathrm{~mm}$ and $0.1 \mathrm{cN}$ respectively. Consumption values measured using length meter were verified through stitch unraveling method. Actual thread lengths were measured using crimp tester adhering to the procedures in the test standard ASTM D3883, standard test method for yarn crimp and yarn take-up in woven fabrics (ASTM International 2012). All the tension values were measured at the positions closer the needle as specified in the tension meter manual.

All experiments were designed by selecting different value ranges of concerned parameters. The value ranges of stitch density, yarn count and fabric thickness were selected in a manner that as they enable a balance stitch in all the sewn specimens. Table 1 includes these input parameters and the set up values for each experiment. Each stitch was sewn as $50 \mathrm{~cm}$ burst lengths and three equal segments were then cut from each $50 \mathrm{~cm}$ specimen to measure the length. In here, authors set their test specimens as $10 \mathrm{~cm}$ length stitch segments, ignoring the start and end segments to avoid

Table 1 Experimental parameters

\begin{tabular}{ll}
\hline Variable & Values used \\
\hline Stitch density ( $\mathrm{n}$ stitches per inch) & $8,10,12$ \\
Yarn count of threads (c Tex) & $18.24,37.12,42.27$ \\
Fabric plies thickness (e mm) & $0.3,0.6,0.9$ \\
\hline
\end{tabular}

Source: Author constructed. 


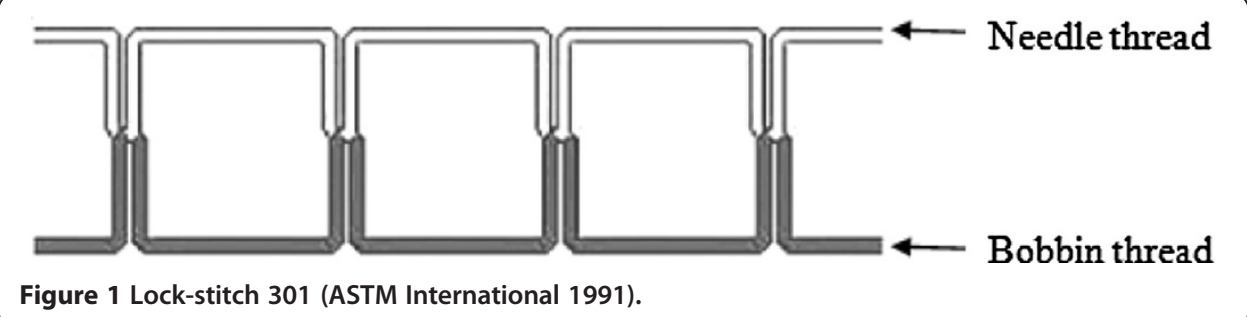

the error of tension fluctuations occur in acceleration and deceleration in each burst of stitching. In this study, authors used 80 and 70 test specimens for lock-stitch 301 (figure 1) and chain-stitch 401 (figure 2) respectively under different combinations of input variables (see Table 1) to satisfy the correct balance and quality appearance.

Curve fitting techniques and multiple linear regression analysis were conducted using SPSS16 16 statistical package to evaluate the influence of thread tension for thread consumption. All the regression models were accepted only when following conditions were satisfied. 1) $R^{2}>0.75,2$ ) significance of the model is accepted through the $p$ value $<0.05$ at $95 \%$ confidence level, 3) Corresponding coefficient for the variables should be individually significant at 95\% confidence level, 4) VIF values for checking multicollinearity of independent variables should be greater than 5 to decide that variables got multi-collinearity effect, and 5) acceptance from the residual analysis for the model fitted. The study was carried out to analyze the correlation between thread tension and thread consumption of two different stitches. The thread consumption was denoted as $\mathrm{D}$ in millimeters per $10 \mathrm{~cm}$ stitching length for a given thread in a given stitch. As example, $\mathrm{D}_{301}$, needle denotes the consumption (in millimeters) of needle thread for lockstitch 301 once it has been made $10 \mathrm{~cm}$ stitch length.

\section{Results and discussion}

Results of multiple linear regression analysis displayed significant effect from tension of the needle thread as a combinatorial effect of tension together with another input variable. A fine and strongly significant model was possible with $R^{2}=0.94$, when the variable thread tension incorporated with another variable as in equation 1 . The derived formula for lockstitch 301 is denoted in equation 1.

$\mathrm{D}_{301, \text { needle }}=0.281 \mathrm{n}+0.001 \mathrm{cT}+2.041 \mathrm{e}+6.42$

Where:

$\mathrm{D}=$ Thread consumption in millimeters per $10 \mathrm{~cm}$ stitching length

$\mathrm{n}=$ Stitch density measured in stitches per inch

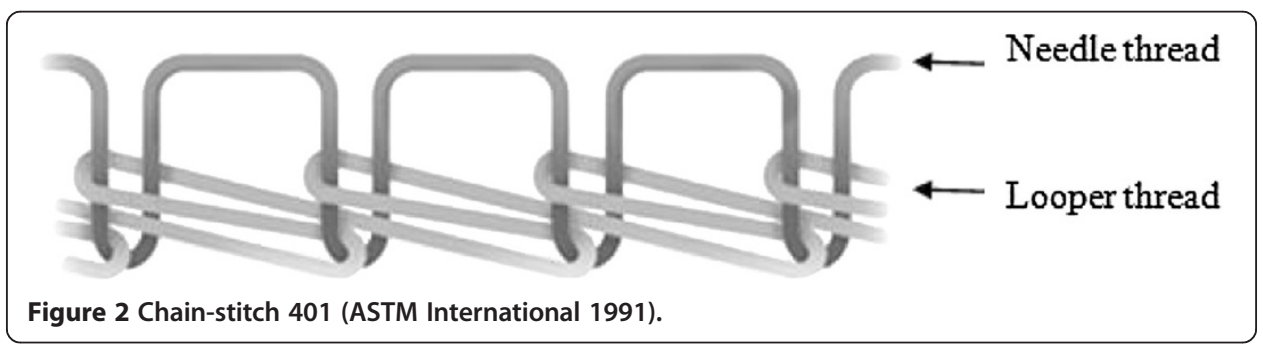


$\mathrm{c}=$ Linear density of sewing thread measured in Tex

$\mathrm{e}=$ Thickness of the fabric measured in millimeters

$\mathrm{T}=$ Tension measured in $\mathrm{cN}$

Since lock-stitch 301 is a well-balanced stitch in nature (Figure 1), theoretically both needle and bobbin threads have to be equal in length and average tension values. However, previous studies states that practically the average tension values of needle and bobbin threads are not equal, where the average tension of needle thread is slightly higher than the bobbin thread (Dorkin \& Chamberlain 1962). In calculations, the consumption value and tension value of bobbin thread was considered as equal as needle thread due to the limitations of measuring consumption and tension values of bobbin thread.

In case of chain-stitch 401, results depicted that tension of needle thread and looper thread can influence on the consumption values. Equation 2 and 3 summarize the experimental data values for chain-stitch 401 threads with corresponding $R^{2}$ values 0.894 and 0.906 respectively.

Needle-thread consumption of chain-stitch 401:

$$
\mathrm{D}_{401, \text { needle }}=0.25 \mathrm{nT}+4.137 \mathrm{c}+4.836 \mathrm{eT}-4.154 \mathrm{~T}+61.027
$$

Looped-thread consumption of chain-stitch 401:

$$
\mathrm{D}_{401, \text { looper }}=2.312 \mathrm{n}+2.623 \mathrm{c}+2.53 \mathrm{~T}+351.32
$$

If chain-stitch 401 is well balanced, as figure illustrates, the needle-thread consumption would be defined by the fabric thickness, where the looper-thread consumption would not be affected by the fabric thickness since looper thread is formed under the bottom ply of the seam. According to the results, thread tension has significant effect on thread consumption for chain-stitch 401.

Based on these formulae in equation 1,2 and 3, the average error percentages were calculated for each thread of each stitch and Table 2 depicts the error percentages of new formulae with respect to the available techniques. Results show that the new derived formula has less error percentage compared to the previous studies and commercial thread demand software.

When the multi co-linearity effect was analyzed, it was observed that there are interrelationships between the following variables. 1) stitch density and tension in lockstitch 301 needle-thread, chain-stitch 401 needle-threads and chain-stitch 401 looperthread, and 2) fabric thickness and tension in lock-stitch 301 needle-thread and chainstitch 401 needle-thread.

\section{Conclusions}

The proposed new parameter; thread tension being experimented using standard procedures for two main types of stitches namely lock-stitch 301 and chain-stitch 401. For both stitches, thread tension affects significantly in determination of thread consumption. In case of chain-stitch 401, there are combined effects of thread tensions together with fabric thickness and stitch density which determines accurate consumption values considering the properties of the stitch. The analysis of lock-stitch 301 shows a joint effect of thread tension and yarn count to the consumption of the needle thread. In 
Table 2 Comparison of error percentages with current study and previous studies

\begin{tabular}{lll}
\hline Method & Lock-stitch $\mathbf{3 0 1}$ & Chain-stitch $\mathbf{4 0 1}$ \\
\hline Geometric Method (Jaouadi et al. 2006) & $34.54 \%$ & $14.51 \%$ \\
Commercial thread consumption software (American \& Efird Inc.) & $13.10 \%$ & $12.71 \%$ \\
Statistical model used in previous research (Jaouadi et al. 2006) & $7.98 \%$ & $6.78 \%$ \\
Derived Formulae (current study) & $5.72 \%$ & $4.85 \%$ \\
\hline
\end{tabular}

Source: Author constructed.

comparison, inclusion of proposed thread tension variable depicts reduction in error percentages, so that the proposed formulae are expected to be a better approach to calculate thread consumption of lock-stitch 301 and chain-stitch 401. Once tension parameter is included in the formulae, apparel manufacturers need to optimize and measure the tension during garment pre-production stage as specified for the geometric requirement of the stitch. The average tension value set for a given stitch under selected stitch density can be measured using MLT Wesco tension meter and that figure need to be substituted in calculating the thread consumption. If researchers are able to introduce a standard table which represents average tension values which determine the correct geometry of the stitches under different stitch density levels, industry personnel or software system can easily refer such table and substitute the tension values to the proposing formulae.

The proposed investigation is limited only for two basic types of stitches and usage only those two is not adequate to apply them in apparel business environment where several types of stitches are used. The investigation need to be extended for all 6 classes of stitches so that industry will be able to use deriving formulae in an effective way. For instance, the proposed formulae will perform under the defined value ranges of corresponding parameters and further analysis would minimize these constrains. Investigation of learning algorithm such as neural network analysis, forecasting mechanism with more parameters such as thread tension, fabric tension, and thread elongation will be the suggesting areas to explore as future methods of sewing thread consumption predictions.

Competing interests

The authors declare that they have no competing interests.

Authors' contributions

RPA and GLDW conceived and designed the experiments. RPA performed the experiments and analyzed the data. Both authors contributed to the writing of the manuscript. Both authors read and approved the final manuscript.

Received: 9 April 2014 Accepted: 20 August 2014

Published: 22 August 2014

References

Amann Group. (2010). Determining your Sewing Thread Requirements. Retrived December 23, 2010. from http://www.amann. com/fileadmin/download/naehfaden/b_naehfadenbedarf_EN.pdf.

American \& Efird Inc. (2007). Technical Bulletin Estimating Thread Consumption. Retrived October 15, 2010. from http://www.amefird.com/wp-content/uploads/2009/10/Stitch-Type-Matrix.pdf estthrd consumption.

Amirbayat, J, \& Alagha, MJ. (1993). Further studies on balance and thread consumption of lockstitch seams. International Journal of Clothing Science \& Technology, 5(2), 26-31.

ASTM International. (1991). ASTM D6192: Reference Guide of Most Common Stitch Types. Philadelphia, USA: American Society for Testing and Materials.

ASTM International. (1997). ASTM D1907: Standard Method of Test for Yarn Number by the Skein Method. Philadelphia USA: American Society for Testing and Materials.

ASTM International. (2011). ASTM D6193: Standard Practice for Stitches and Seams. Philadelphia, USA: American Society for Testing and Materials. 
ASTM International. (2012). ASTM D3883: Standard Test Method for Yarn Crimp and Yarn Take-Up in Woven Fabrics. Philadelphia, USA: American Society for Testing and Materials.

British Standards Institution. (1987). BS2544: Methods for determination of thickness of textile materials. London: British Standards Institution.

Carr, H, \& Latham, B. (1994). The Technology of Clothing Manufacture (2nd ed.). Oxford: Wiley-Blackwell.

Dorkin, CMC, \& Chamberlain, NH. (1962). Technological Report no. 11. London: Clothing Institute.

Ferreira, FBN, Harlock, SC, \& Grosberg, P. (1994a). A study of thread tensions on a lockstitch sewing machine (part I). International Journal of Clothing Science and Technology, 6(1), 14-19.

Ferreira, FBN, Harlock, SC, \& Grosberg, P. (1994b). A study of thread tensions on a lockstitch sewing machine (part II). International Journal of Clothing Science and Technology, 6(5), 26-29.

Ferreira, FBN, Harlock, SC, \& Grosberg, P. (1994c). A study of thread tensions on a lockstitch sewing machine (part III). International Journal of Clothing Science and Technology, 6(5), 39-42.

Ghosh, S, \& Chavhan, MV. (2014). A geometrical model of stitch length for lockstitch seam. Indian Journal of Fibre \& Textile Research, 39, 153-156.

Hayes, SG. (2001). The effects of check-spring travel on lockstitch sewing. Research Journal of Textile and Apparel, $5(2), 54-64$.

Jaouachi, B, Khedher, F, \& Mili, F. (2012). Consumption of the sewing thread of jean pant using taguchi design analysis. AUTEX Research Journal, 12(4), 81-86.

Jaouadi, M, Msahli, S, Babay, A, \& Zitouni, B. (2006). Analysis of the modeling methodologies for predicting the sewing thread consumption. International Journal of Clothing Science and Technology, 18(1), 7-18.

Kennon, WR, \& Hayes, SG. (2000). The effects of feed retardation on lockstitch sewing. Journal of the Textile Institute, 91(4), 509-522.

Krishnan, ANS, \& Kumar, LA. (2010). Design of sewing thread tension measuring device. Indian Journal of Fibre and Textile Research, 35(1), 65-67.

O'Dwyer, U, \& Munden, DL. (1975). A study of the factors effecting the dimensions and thread consumption in 301 seams - part I. Clothing Research Journal, 3(1), 3-32.

Rasheed, A, Ahmad, S, Mohsin, M, Ahmad, F, \& Afzal, A. (2014). Geometrical model to calculate the consumption of sewing thread for 301 lockstitch. The Journal of The Textile Institute. doi:10.1080/00405000.2014.886366.

Rengasamy, RS, \& Samuel, WD. (2011). Effect of thread structure on tension peaks during lock stitch sewing. AUTEX Research Journal, 11(1), 1-5.

Samuel, WD, \& Poojitha, V. (2010). A simple system for the online detection of skip/loop stitches in single needle lockstitch machines. AUTEX Research Journal, 10(3), 69-72.

Ukponmwan, JO, Mukhopadhyay, A, \& Chatterjee, KN. (2000). Sewing threads (Textile Progress). Manchester: Textile Institute.

Weimer, C, \& Mitschang, P. (2001). Aspects of stitch formation process of the quality of sewn multi-textile-performs. Composites Part A: Applied Science and Manufacturing, 32, 1477-1484.

doi:10.1186/s40691-014-0014-5

Cite this article as: Abeysooriya and Wickramasinghe: Regression model to predict thread consumption incorporating thread-tension constraint: study on lock-stitch 301 and chain-stitch 401. Fashion and Textiles 2014 1:14.

\section{Submit your manuscript to a SpringerOpen ${ }^{\circ}$ journal and benefit from:}

- Convenient online submission

- Rigorous peer review

- Immediate publication on acceptance

- Open access: articles freely available online

- High visibility within the field

- Retaining the copyright to your article

Submit your next manuscript at $\boldsymbol{\nabla}$ springeropen.com 